\title{
A Complete Expression Profile of Matrix-Degrading Metalloproteinases in Dupuytren's Disease
}

\author{
Phillip Johnston, MB BChir, Adrian J. Chojnowski, MB BChir, \\ Rose K. Davidson, BSc, Graham P. Riley, PhD, Simon T. Donell, MD, \\ Ian M. Clark, PhD
}

From the Institute of Orthopaedics, Norfolk and Norwich University Hospital, Norwich, UK; School of Biological Sciences, University of East Anglia, Norwich, UK; and the Rheumatology Research Unit, Addenbrooke's Hospital, Cambridge, UK.

Purpose: Dupuytren's disease (DD) is a common fibrotic condition of the palmar fascia, leading to deposition of collagen-rich cords and finger contractions. The metzincin superfamily contains key enzymes in the turnover of collagen and other extracellular matrix macromolecules. A number of broad-spectrum matrix metalloproteinase inhibitors, used in cancer clinical trials, caused side effects of DD-like contractures. We tested the hypothesis that changes in the expression of specific metalloproteinases underlie or contribute to the fibrosis and contracture seen in DD.

Methods: We collected tissue from patients with DD and used normal palmar fascia as a control. We profiled the expression of the entire matrix metalloproteinase (MMP), tissue inhibitor of metalloproteinases (TIMP), and a disintegrin and metalloproteinase domain with thrombospondin motif (ADAMTS) gene families in these tissues using real-time reversetranscription polymerase chain reaction.

Results: A number of metalloproteinases and inhibitors are regulated in DD. The expression of 3 key collagenases, MMP1, MMP13, and MMP14 is increased significantly in the DD nodule, as is the expression of the collagen biosynthetic enzyme ADAMTS14. The expression of $M M P 7$, an enzyme with broad substrate specificity, is increased in the DD nodule and remains equally expressed in the DD cord. TIMP1 expression is increased significantly in DD nodule compared with normal palmar fascia.

Conclusions: This study measured the expression of all MMP, ADAMTS, and TIMP genes in DD. Contraction and fibrosis may result from: (1) increased collagen biosynthesis mediated by increased ADAMTS-14; (2) an increased level of TIMP-1 blocking MMP-1- and MMP13-mediated collagenolysis; and (3) contraction enabled by MMP-14-mediated pericellular collagenolysis (and potentially MMP-7), which may escape inhibition by TIMP-1. The complete expression profile will provide a knowledge-based approach to novel therapeutics targeting these genes. (J Hand Surg 2007;32A:343-351. Copyright (C) 2007 by the American Society for Surgery of the Hand.)

Key words: ADAMTS, Dupuytren's disease, gene expression, MMP, TIMP.

$\mathrm{D}$ upuytren's disease (DD) is a common condition with $4 \%$ to $6 \%$ of Caucasian populations having evidence of disease, ${ }^{1}$ and affecting up to $20 \%$ of men older than 65 years of age. ${ }^{2}$ Clinically it is characterized by fibrosis of the palmar fascia; progression and potentially onset of the disease involves the formation and proliferation of myofibroblasts. Three distinct histologic phases have been described, ${ }^{3}$ with a proliferative phase leading to the development of a nodular lesion, an involutional phase in which cells align themselves to lines of stress, and a residual phase leaving a scar-like cord tissue. Thus, the nodules are thought to represent an active phase of disease with myofibroblast proliferation, whereas the cords represent late-stage disease and the absence of myofibroblasts. 
The matrix metalloproteinases (MMPs) are a family of 23 enzymes in human beings that include the only mammalian enzymes able to degrade the collagen triple helix in a specific manner under physiologic conditions. ${ }^{4}$ The classic collagenases are MMP-1, -8 , and -13 of the human enzymes. More recently, MMP-2 (gelatinase A) and MMP-14 (MT1MMP) also have been shown to make this specific cleavage, although with less catalytic efficiency. ${ }^{5-7}$ Other MMPs also have been implicated in collagen turnover (eg, MMP-3, by virtue of its ability to activate the pro-enzyme form of MMP-1). ${ }^{8}$ A related family of metalloproteinases, a disintegrin and metalloproteinase domain with thrombospondin motif (ADAMTSs), have 19 members in human beings and also are implicated in extracellular matrix (ECM) metabolism. These include enzymes capable of degrading the proteoglycan, aggrecan (at least ADAMTS-1, -4, -5, -8, -9, and -15), and 3 procollagen N-propeptidases (ADAMTS-2, -3, and -14). Many other members of this family are of unknown function. ${ }^{9}$ A family of 4 specific inhibitors, the tissue inhibitors of metalloproteinases (TIMPs), have been described. ${ }^{10}$ Although the ability of the 4 TIMPs to inhibit MMPs is largely promiscuous, a number of functional differences have been noted; for example, TIMP-2, -3 , and -4 , but not TIMP-1, are effective inhibitors of the membrane-type metalloproteinase (MT-MMP) subclass. Specificity among the TIMPs for inhibition of the ADAMTS family of metalloproteinases also has been described, with TIMP-3 being a potent inhibitor of ADAMTS-4 (aggrecanase-1) and ADAMTS-5 (aggrecanase-2). ${ }^{11}$ In many fibrotic diseases such as those affecting the liver, lung, and skin, MMPs (and related metalloproteinases) and TIMPs play an important role. Normal ECM turnover can be viewed as a balance between proteinase and inhibitor activities, with fibrosis coming from an imbalance away from proteolysis. $^{4}$

In the 1980s and 1990s, several small molecule inhibitors of MMPs were involved in clinical trials in a variety of cancers. ${ }^{12}$ The major side effect of these drugs was a so-called musculoskeletal syndrome, often referred to as musculoskeletal pain accompanied by tendonitis. ${ }^{13,14}$ This was doseand time-dependent and reversible on treatment discontinuation, but did not respond well to nonsteroidal anti-inflammatory drugs or low-dose steroid treatment. The clinical presentation, when reported in detail, is described as frozen shoulder or a condition resembling DD. ${ }^{15}$ Both of these con- ditions involve similar fibrotic mechanisms (of the shoulder joint capsule in the case of frozen shoulder), the laying down of a collagen-rich ECM, and the involvement of myofibroblast-mediated contraction. ${ }^{16,17}$ Although DD and frozen shoulder have different natural histories (the former a progressive disease, the latter usually self-limiting and resolving in time), they may well share common pathways leading to contracture. ${ }^{16}$ The MMP inhibitors that cause the musculoskeletal syndrome are pan-MMP inhibitors, showing an approximately nanomolar (or lower) inhibition constant against many of the MMPs tested. Moreover, there is good evidence that they also may inhibit related metalloproteinases (eg, ADAMTSs). Indeed, the musculoskeletal syndrome usually is ascribed to the inhibition of nontarget metalloproteinases.

The measurement of a small subset of MMPs and TIMPs (MMP-1, -2, -9, TIMP-1 and -2) in the sera of patients with DD, compared with patients who had carpal tunnel release, lends some support to the tenet that expression of these enzymes is altered in DD. ${ }^{18}$ Patients with DD had significantly higher serum TIMP-1 levels and the investigators ${ }^{18}$ suggested that there is a systemic change in the MMP-to-TIMP ratio that may lead to increased collagen deposition. A microarray analysis of gene expression in DD and Peyronie's disease, compared with normal palmar fascia and tunica albuginea, respectively, showed upregulation of $M M P 2$ and $M M P 9$ in diseased tissue. ${ }^{19}$ A reverse-transcription polymerase chain reaction (PCR)-based comparison of Dupuytren's tissue with frozen shoulder or control shoulder tissues showed expression of $M M P 1, M M P 2, M M P 9$, and TIMP1 in all tissues, with MMP3 absent from DD tissue and MMP14 increased compared with shoulder tissue. $^{20}$ An earlier report also showed an increased expression of MMP-2 and MMP-9 in Dupuytren's tissue in response to mechanical load. ${ }^{21}$ None of these studies were able to look at all members of the MMP, TIMP, and related metalloproteinase gene families.

From these data we proposed the hypothesis that MMPs, ADAMTSs, and TIMPs may play a key role in the onset or progression of DD and related disorders. Hence, we used a quantitative reverse-transcription PCR methodology to profile the expression of all members of the MMP, ADAMTS, and TIMP families in nodule and cord tissue from DD patients and compared this with normal palmar fascia taken at carpal tunnel release. 


\section{Materials and Methods}

Tissue Samples

All surgery was performed at the Norfolk and Norwich University Hospital under approval from the local research ethics committee and all patients gave informed consent. Tissue from patients with DD was taken at fasciectomy $(n=20$; age range, $42-83$ y; 3 women, 20 men). Samples were divided into regions of nodule and cord according to gross morphology. Normal palmar fascia was taken from patients without DD who had carpal tunnel release $(n=20$; age range, 25-84 y; 17 women, 3 men). Tissue was dissected into approximately $5-\mathrm{mm}$ pieces and snap frozen in liquid nitrogen within 15 to 30 minutes of surgery.

\section{RNA Extraction}

Tissue was weighed and homogenized in reagent (TRIzol; Invitrogen Paisley, UK) (1 mL/0.1 g tissue) using an homogenizer (UltraTurrax, IKA, Staufen, Germany). Particulates were pelleted at $10,000 \mathrm{~g}$ for 10 minutes at $4{ }^{\circ} \mathrm{C}$ and the supernatant was recovered. A total of $600 \mu \mathrm{L}$ chloroform was added per $1 \mathrm{~mL}$ TRIzol, vortexed for 15 seconds, and incubated at room temperature for 10 minutes. The TRIzol/chloroform solution was centrifuged at $10,000 \mathrm{~g}$ for 15 minutes at $4{ }^{\circ} \mathrm{C}$ and the aqueous layer was placed into a fresh tube. A total of $0.5 \times$ volume of $100 \%$ ethanol was added and mixed. Samples were applied to spin columns (RNeasy Mini Kit; Qiagen, Crawley, West Sussex, UK), centrifuged at full speed for 15 seconds, and the flow through was discarded as described by Price et al. ${ }^{22}$ Columns then were washed and eluted according to the manufacturer's instructions. RNA samples were quantified using a spectrophotometer (NanoDrop; NanoDrop Technologies, Wilmington, DE) and stored at $-80^{\circ} \mathrm{C}$.

\section{Synthesis of Complementary DNA}

Complementary DNA was synthesized from $1 \mu \mathrm{g}$ of total RNA using reverse transcriptase (Superscript II, Invitrogen) and random hexamers in a total volume of $20 \mu \mathrm{L}$ according to the manufacturer's instructions. Complementary DNA was stored at $-20^{\circ} \mathrm{C}$ until used in downstream PCR.

Quantitative Real-Time

Polymerase Chain Reaction

Oligonucleotide primers and fluorescent-labeled probes were designed (Primer Express 1.0 software; Applied Biosystems, Warrington, UK). Sequences for $M M P$ and TIMP primers and probes were as described by Nuttall et $\mathrm{al}^{23}$ and ADAMTS primers and probes were as described by Porter et al. ${ }^{24}$ To control against amplification of genomic DNA, primers were placed within different exons close to an intron/exon boundary, with the probe spanning 2 neighboring exons where possible. Basic Local Alignment Search Tool (BLAST) searches for all the primer and probe sequences also were conducted to ensure gene specificity. The $18 \mathrm{~S}$ ribosomal RNA (rRNA) gene was used as an endogenous control to normalize for differences in the amount of total RNA present in each sample; $18 \mathrm{~S}$ rRNA primers and probe were purchased from Applied Biosystems.

The relative quantification of genes was performed using the ABI Prism 7700 sequence detection system (Applied Biosystems) in accordance with the manufacturer's protocol. Polymerase chain reactions contained $5 \mathrm{ng}$ of reverse-transcribed RNA (1 $\mathrm{ng}$ for $18 \mathrm{~S}$ analyses), $50 \% 2 \mathrm{X}$ Master Mix (Tagman 2X Master Mix, Applied Biosystems), $100 \mathrm{nmol} / \mathrm{L}$ of each primer, and 200 $\mathrm{nmol} / \mathrm{L}$ of probe in a total volume of $25 \mu \mathrm{L}$. Conditions for the PCR reaction were 2 minutes at $50^{\circ} \mathrm{C}, 10$ minutes at $95^{\circ} \mathrm{C}$, then 40 cycles each consisting of 15 seconds at $95^{\circ} \mathrm{C}$ and 1 minute at $60^{\circ} \mathrm{C}$.

The threshold cycle $\left(\mathrm{C}_{\mathrm{T}}\right)$, the cycle number at which the signal is detectable above the baseline, was transformed in 2 ways. To gain an approximate comparison across all genes measured, the amplification efficiency was assumed to be identical across all primer sets and normalized to $18 \mathrm{~S}$ expression using a transformation proportional to normalized copy number $\left(2^{-\Delta C_{T}}\right)$, where $\Delta C_{T}$ is $C_{T}$ (target gene) $-C_{T}$ (18S). When comparing the expression of a single gene across sample groups, standard curves for each gene were generated using the complementary DNA (cDNA) from one sample and making 2-fold serial dilutions across an appropriate range. Relative input amounts of template cDNA then were calculated from $\mathrm{C}_{\mathrm{T}}$ using the standard curves; data are presented as relative levels of messenger RNA (mRNA) normalized to $18 \mathrm{~S}$ rRNA. As a final quality control for the purified RNA samples, only those cDNAs within \pm 1.5 $\mathrm{C}_{\mathrm{T}}$ of the median value for $18 \mathrm{~S}$ for all samples were used in the downstream study.

To ascertain that the amplification product was indeed that of the desired target gene, products were subcloned and sequenced. All primer and probe sets have been shown to amplify specific products from appropriate human tissue samples. $^{23,24}$ 


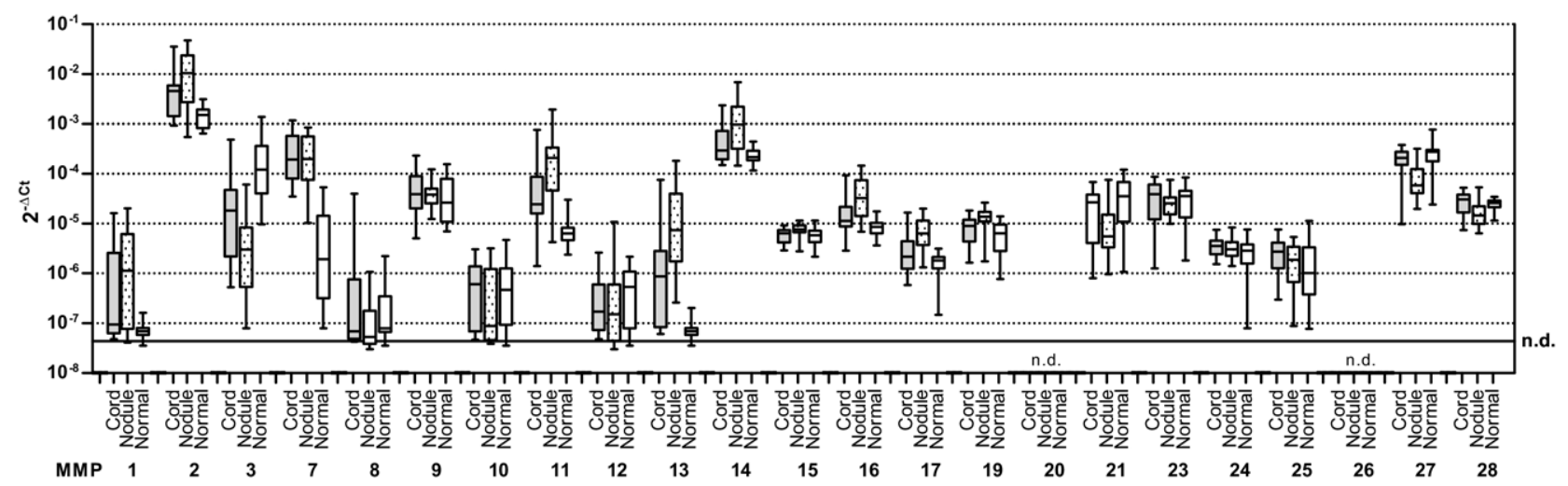

Figure 1. Comparative expression of MMP genes in normal palmar fascia versus cord and nodule tissue from DD. The expression level of each gene was determined as described in the Materials and Methods section and normalized to the level of $18 S$ rRNA gene expression using $\Delta \mathrm{C}_{\mathrm{T}}\left(\mathrm{C}_{\mathrm{T}}\right.$ [target gene] - $\mathrm{C}_{\mathrm{T}}$ [18S]). Open boxes, normal; filled boxes, cord; dotted boxes, nodule. The box-and-whisker plot shows the median, and each section represents a quartile of the data. N.D., not detected.

\section{Statistical Analysis}

Analyses were performed on 19 samples from each group because 1 sample in each group failed quality control as detailed previously. Differences between the 3 groups were defined using a Kruskal-Wallis test or pair-wise comparison using a 2-sided MannWhitney U test (in GraphPad Prism 4; GraphPad Software Inc, San Diego, CA); these nonparametric tests make no prior assumption on the data distribution. To account for differences in age and gender, standardized expression data using the standard curve method were subjected to a logarithmic transformation to approximate normalization and tested by analysis of covariance (ANCOVA; SPSS for Windows; SPSS Inc, Chicago, IL). Further analysis of correlation was performed using the Spearman rank correlation (SPSS for Windows).

\section{Results}

Examining the overall pattern of gene expression shown in Figures 1 to 3, a striking feature is that the level of TIMP gene expression is higher than that of the proteinase genes. Broadly, the level of steadystate mRNA across the 3 gene families assayed is TIMP $>$ ADAMTS $>M M P$. Table 1 shows the differences in gene expression between the DD nodule and cord tissue compared with normal palmar fascia.

Although DD obviously involves the laying down of excess collagenous matrix, this matrix is presumably also remodeled and shortened during disease

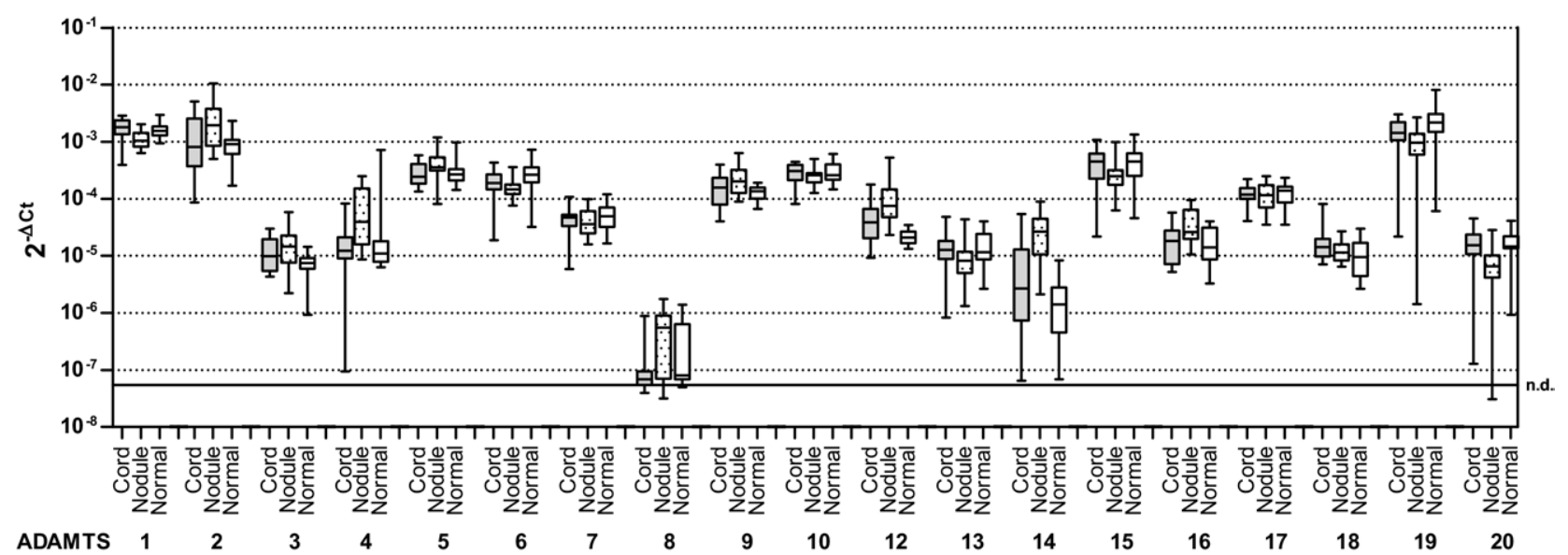

Figure 2. Comparative expression of ADAMTS genes in normal palmar fascia versus cord and nodule tissue from DD. The expression level of each gene was determined as described in the Materials and Methods section and normalized to the level of $18 \mathrm{~S} r R N A$ gene expression using $\Delta \mathrm{C}_{\mathrm{T}}\left(\mathrm{C}_{\mathrm{T}}\right.$ [target gene] - $\mathrm{C}_{\mathrm{T}}$ [18S]). Open boxes, normal; filled boxes, cord; dotted boxes, nodule. The box-and-whisker plot shows the median, and each section represents a quartile of the data. N.D., not detected. 


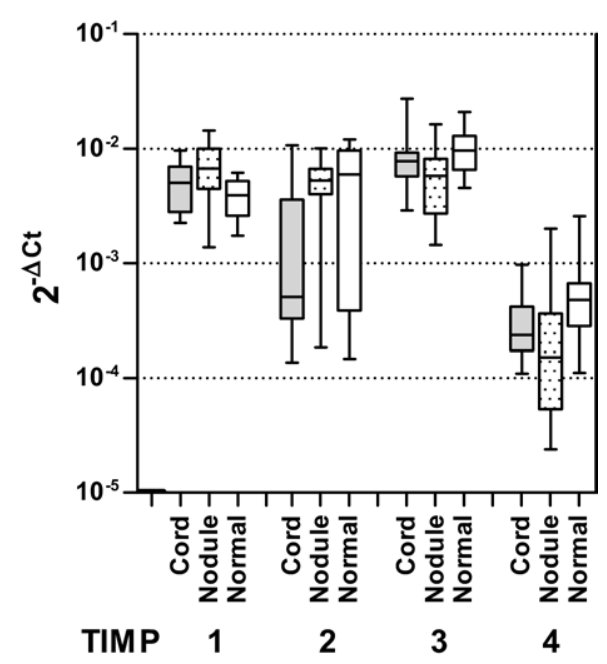

Figure 3. Comparative expression of TIMP genes in normal palmar fascia versus cord and nodule tissue from DD. The expression level of each gene was determined as described in the Materials and Methods section and normalized to the level of $18 S$ rRNA gene expression using $\Delta \mathrm{C}_{\mathrm{T}}\left(\mathrm{C}_{\mathrm{T}}\right.$ [target gene] - $C_{T}$ [18S]). Open boxes, normal; filled boxes, cord; dotted boxes, nodule. The box-and-whisker plot shows the median, and each section represents a quartile of the data.

progression either as a consequence of tension or contributing to increased tension. Thus, the expression of 3 procollagen N-propeptidases, ADAMTS2, $A D A M T S 3$, and particularly ADAMTS14, is increased in the DD nodule, consistent with an increase in collagen synthesis. Conversely, the expression of several enzymes capable of mediating collagen breakdown, $M M P 1, M M P 2, M M P 13$, and $M M P 14$, also is increased in the DD nodule compared with normal palmar fascia, consistent with increased collagen turnover. The increase of all of the earlier-described enzymes is to some extent attenuated in the DD cord.

Comparing the DD nodule with the cord, it is clear that many genes that are induced in the nodule are at least less induced in the cord, with many not significantly different in the cord compared with normal palmar fascia. The only gene whose expression is increased in the DD nodule and remains increased to a similar level in the DD cord is MMP7; MMP-7 has a broad substrate specificity, ${ }^{25}$ and this may represent a continued matrix remodeling process in the DD cord (see later).

The most significantly downregulated gene in the DD nodule is $M M P 3$. This appears to be a recurring theme in diseases involving matrix destruction because similar findings have been reported in osteoarthritic cartilage ${ }^{26}$ and degenerative tendinopathy. ${ }^{27}$

Six ADAMTS enzymes have been shown to be aggrecanases, at least in vitro, ADAMTS-1, ADAMTS-4,
ADAMTS-5, ADAMTS-8, ADAMTS-9, and ADAMTS-15. ADAMTS15 is expressed in normal palmar fascia, but not regulated in DD tissue. ADAMTS4, ADAMTS5, and ADAMTS9 all are expressed in normal palmar fascia and increased in the DD nodule, but not the cord. ADAMTS1 is expressed robustly in normal palmar fascia and expression is lower in the DD nodule. ADAMTS8 is undetectable in most tissue samples.

Of the TIMPs, TIMP1 expression is increased in the DD nodule, but TIMP2, TIMP3, and TIMP4 all are expressed at lower levels in the DD nodule than in normal palmar fascia.

Analysis of covariance showed that there is a relationship between the patient's age and the level of gene expression for MMP3, MMP16, MMP17, MMP25, TIMP1, TIMP2, ADAMTS1, ADAMTS5, and ADAMTS18. Analysis of covariance also showed a weak relationship between gender and expression of MMP16, TIMP2, ADAMTS3, and ADAMTS5. The statistically significant differences in gene expression for these genes between groups (detailed previously), however, are paralleled in this analysis in all cases apart from ADAMTS18. The expression of ADAMTS18 shows no statistical difference between groups under ANCOVA analysis but shows weak significance when analyzed by either Kruskal-Wallis or in pair-wise analysis using the Mann-Whitney $U$ test. For the expression of $M M P 3, T I M P 1$, and TIMP2, there is a strong correlation with age in normal palmar fascia (the former 2 decreasing with age, the latter increasing) that is lost in DD tissues. This shows that regulatory mechanisms for these genes are aberrant in disease. Table 2 shows a Spearman rank correlation analysis for the 9 genes showing an effect of age in ANCOVA. Figure 4 shows the correlation of $M M P 3$ expression with age in the normal palmar fascia.

\section{Discussion}

In screens of gene expression the need to account for multiple testing in the statistical analyses is problematic. The Bonferroni correction is often conservative, removing type I error (false positive) at the expense of type II error (false negative). This would limit the utility of gene expression studies in which the validity of any multiple testing procedure has yet to be ascertained. ${ }^{28,29}$ In Table 1, we have not applied any correction for multiple testing, although at the 5\% significance level $(\mathrm{p}=.05)$ a false-positive rate of 1 in 20 would be expected.

Of prime importance to the phenotypic outcome of these changes in gene expression is the final balance 
Table 1. Comparison of Gene Expression Between Normal Palmar Fascia, Cord, and Nodule Tissue From DD

\begin{tabular}{|c|c|c|c|c|c|c|}
\hline \multirow{3}{*}{$\begin{array}{r}\text { Gene } \\
M M P 1\end{array}$} & \multicolumn{6}{|c|}{ $\pm p$ value } \\
\hline & \multicolumn{2}{|c|}{$\begin{array}{l}\text { Normal versus nodule } \\
(+, \text { higher in nodule })\end{array}$} & \multicolumn{2}{|c|}{$\begin{array}{l}\text { Normal versus cord } \\
(+, \text { higher in cord })\end{array}$} & \multicolumn{2}{|c|}{$\begin{array}{l}\text { Nodule versus cord } \\
(+, \text { higher in cord })\end{array}$} \\
\hline & + & .0009 & & NS & & NS \\
\hline MMP2 & + & $<.0001$ & + & .0043 & - & .0043 \\
\hline MMP3 & - & $<.0001$ & - & .0002 & + & .0091 \\
\hline$M M P 7$ & + & $<.0001$ & + & $<.0001$ & & NS \\
\hline МMP8 & & NS & & NS & + & .044 \\
\hline MMP9 & & NS & & NS & & NS \\
\hline MMP10 & & NS & & NS & & NS \\
\hline MMP11 & + & $<.0001$ & + & $<.0001$ & - & .004 \\
\hline MMP12 & & NS & & NS & & NS \\
\hline MMP13 & + & $<.0001$ & + & .0003 & - & .0012 \\
\hline MMP14 & + & $<.0001$ & & NS & - & .0061 \\
\hline MMP15 & + & .0144 & & NS & - & .0098 \\
\hline MMP16 & + & $<.0001$ & + & .036 & - & .004 \\
\hline MMP17 & + & $<.0001$ & & NS & - & $<.0001$ \\
\hline MMP19 & + & $<.0001$ & & NS & - & .0028 \\
\hline MMP20 & & ND & & ND & & ND \\
\hline MMP21 & + & .0071 & & NS & & NS \\
\hline MMP23 & & NS & & NS & & NS \\
\hline MMP24 & & NS & & NS & & NS \\
\hline MMP25 & & NS & & NS & & NS \\
\hline MMP26 & & ND & & ND & & ND \\
\hline MMP27 & - & .0003 & & NS & + & .002 \\
\hline MMP28 & & NS & & NS & - & .04 \\
\hline ADAMTS1 & - & .011 & & NS & + & .0043 \\
\hline ADAMTS2 & + & .0012 & & NS & - & .012 \\
\hline ADAMTS3 & + & .0034 & + & .018 & & NS \\
\hline ADAMTS4 & + & .0024 & & NS & - & .0005 \\
\hline ADAMTS5 & + & .0066 & & NS & - & .017 \\
\hline ADAMTS6 & - & .0043 & & NS & + & .04 \\
\hline ADAMTS7 & & NS & & NS & & NS \\
\hline ADAMTS8 & - & .0056 & & NS & + & .0043 \\
\hline ADAMTS9 & + & .0037 & & NS & & NS \\
\hline ADAMTS10 & & NS & & NS & & NS \\
\hline ADAMTS12 & + & $<.0001$ & + & .0028 & - & .002 \\
\hline ADAMTS13 & & NS & & NS & & NS \\
\hline ADAMTS14 & + & $<.0001$ & & NS & - & .0002 \\
\hline ADAMTS15 & & NS & & NS & + & .036 \\
\hline ADAMTS16 & + & .0223 & & NS & - & .0024 \\
\hline ADAMTS17 & & NS & & NS & & NS \\
\hline ADAMTS18 & + & .036 & + & .0144 & & NS \\
\hline ADAMTS19 & - & .0056 & & NS & + & .021 \\
\hline ADAMTS20 & - & .0034 & & NS & + & .0031 \\
\hline TIMP1 & + & .0008 & & NS & - & .028 \\
\hline TIMP2 & - & .0115 & & NS & + & .0005 \\
\hline TIMP3 & - & .004 & & NS & & NS \\
\hline TIMP4 & - & .004 & & NS & + & .03 \\
\hline
\end{tabular}

Statistical analysis was performed pair-wise using the Mann-Whitney $U$ test. NS, not significant; ND, not detected.

of proteinase versus inhibitor. Although this is impossible to ascertain from a study at the steady-state mRNA level such as this, it is clear that TIMPI is the only TIMP whose expression is increased signifi- cantly in the DD nodule compared with normal palmar fascia. Indeed, TIMP2, TIMP3, and TIMP4 all are reduced in the DD nodule. Thus, in the DD nodule, the situation may be similar to that described 
in liver fibrosis, in which the potential for matrix degradation is present, even in advanced disease, but is prevented by TIMP expression. ${ }^{30}$ Of potential importance here is the fact that TIMP-1 is a poor inhibitor of MMP-14, MMP-15, MMP-16, and MMP-24. ${ }^{10}$ Because expression of MMP14 and MMP16 is significantly increased in the DD nodule, these proteinases might escape inhibition from TIMP-1. This also may provide a mechanism for collagen remodeling, particularly in the pericellular environment (by MMP-14, a membrane-bound enzyme) during contraction in the presence of TIMP-1. Similarly, MMP-7 (whose expression is increased equally in both the DD nodule and the cord), lacks a C-terminal hemopexin-like domain that is common to most MMPs, decreasing its affinity for at least TIMP- $1,{ }^{31}$ and potentially resisting inhibition in pathology.

Several studies have compared the contractile properties of Dupuytren's cord- or nodule-derived fibroblasts with control cultures. ${ }^{32-35}$ Results varied depending on the model of contraction used, but the consensus appears to be that Dupuytren's fibroblasts can generate significantly increased contractile force compared with control cells, with nodule-derived cells showing greatest contraction. In such models, broad-spectrum synthetic MMP inhibitors have been shown to inhibit contraction, ${ }^{36,37}$ and this is paralleled by the inhibition of wound contraction in a mouse model of skin wound healing. ${ }^{38}$ This latter study also reported a decrease in $\alpha$-smooth muscle actin expression in the presence of the MMP inhibitor. This blockade

\section{Table 2. Correlation of Gene Expression With} Age in Normal Palmar Fascia, Cord, or Nodule Tissue From DD

$p$ value ( $r$ value)

\begin{tabular}{lccc}
\cline { 2 - 4 } \multicolumn{1}{c}{ Gene } & Cord & Nodule & Normal \\
\hline MMP3 & .318 & .273 & $<.001(-.774)$ \\
MMP16 & .204 & .307 & $.063(-.435)$ \\
MMP17 & .322 & $.024(-.516)$ & .616 \\
MMP25 & .323 & .358 & .115 \\
TIMP1 & .632 & .557 & $.012(-.565)$ \\
TIMP2 & .280 & .416 & $.013(.558)$ \\
ADAMTS1 & $.051(.454)$ & .263 & .473 \\
ADAMTS5 & .627 & $.011(-.567)$ & .743 \\
ADAMTS18 & $.022(-.523)$ & .468 & .348
\end{tabular}

Genes shown are those identified by ANCOVA. Statistical analysis was performed using the Spearman rank correlation. The Spearman $r$ value is shown where correlation is significant (positive value indicates an increase in expression with age, negative value indicates a decrease in expression with age).

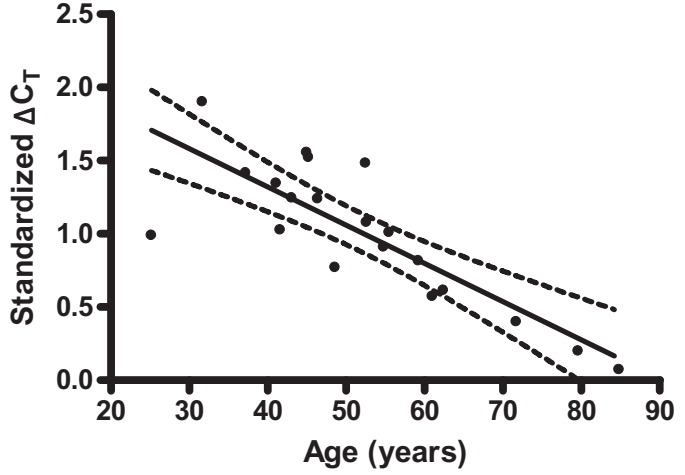

Figure 4. Correlation of $M M P 3$ expression with age in normal palmar fascia. The expression level of MMP3 was determined using the standard curve method as described in the Materials and Methods section and normalized to the level of $18 S r R N A$ gene expression using an adjusted $\Delta \mathrm{C}_{\mathrm{T}}\left(\mathrm{C}_{\mathrm{T}}\right.$ [target gene] - $C_{T}$ [18S], allowing for efficiency of primer-probe sets). The solid line shows the best fit as determined by linear regression, with dotted lines defining 95\% confidence limits.

of contraction is difficult to dovetail with the reported side effects of some of these MMP inhibitors in clinical trials in which Duputyren's-like contracture and frozen shoulder were observed ${ }^{13-15}$; however, this may reflect the fact that culture models of collagen lattice contraction only represent a single facet of a more complex disease process. Again, drawing on the analogy with liver fibrosis, a treatment that downregulates TIMPs but increases the activity of MMPs may be an appropriate therapy for DD. ${ }^{30}$ One such possibility is relaxin, an insulin-like growth factor hormone reported to decrease collagen expression, increase MMP, and decrease TIMP expression in a variety of in vitro and in vivo models. $^{39-42}$

It also may be possible to target collagen biosynthesis via blockade of ADAMTS-14. Functional overlap between the 3 ADAMTS procollagen-Npropeptidases (ADAMTS-2, -3, and -14) provides the potential to inhibit ADAMTS-14 without disruption of global collagen synthesis, ${ }^{43}$ but this may be sufficient to slow or halt collagen deposition in DD.

The current study examines the expression of the entire MMP, ADAMTS, and TIMP families in DD. These enzymes and inhibitors have critical roles in extracellular matrix homeostasis, which is clearly dysregulated in DD. These data will allow future work to focus on the function of specific metalloproteinases in the disease process.

Received for publication October 25, 2006; accepted in revised form December 15, 2006.

The authors received a research grant from Action Arthritis. 
Corresponding author: Ian M. Clark, PhD, School of Biological Sciences, University of East Anglia, Norwich, NR4 7TJ, United Kingdom; e-mail: i.clark@uea.ac.uk.

Copyright (C) 2007 by the American Society for Surgery of the Hand 0363-5023/07/32A03-0007\$32.00/0

doi:10.1016/j.jhsa.2006.12.010

\section{References}

1. Thurston AJ. Dupuytren's disease. J Bone Joint Surg 2003; 85B:469-477.

2. Mikkelsen OA. Epidemiology of a Norwegian population. In: McFarlane RM, McGrouther DA, Flint MH, eds. Dupuytren's disease: biology and treatment. New York: Churchill Livingstone, 1990:191-200.

3. Luck JV. Dupuytren's contracture; a new concept of the pathogenesis correlated with surgical management. J Bone Joint Surg 1959;41A:635-664.

4. Brinckerhoff CE, Matrisian LM. Matrix metalloproteinases: a tail of a frog that became a prince. Nat Rev Mol Cell Biol 2002;3:207-214.

5. Knauper V, Lopez-Otin C, Smith B, Knight G, Murphy G. Biochemical characterization of human collagenase-3. J Biol Chem 1996;271:1544-1550.

6. Ohuchi E, Imai K, Fujii Y, Sato H, Seiki M, Okada Y. Membrane type 1 matrix metalloproteinase digests interstitial collagens and other extracellular matrix macromolecules. J Biol Chem 1997;272:2446-2451.

7. d'Ortho MP, Will H, Atkinson S, Butler G, Messent A, Gavrilovic J, et al. Membrane-type matrix metalloproteinases 1 and 2 exhibit broad-spectrum proteolytic capacities comparable to many matrix metalloproteinases. Eur J Biochem 1997;250:751-757.

8. Murphy G, Cockett MI, Stephens PE, Smith BJ, Docherty AJ. Stromelysin is an activator of procollagenase. A study with natural and recombinant enzymes. Biochem J 1987; 248:265-268.

9. Porter S, Clark IM, Kevorkian L, Edwards DR. The ADAMTS metalloproteinases. Biochem J 2005;386:15-27.

10. Baker AH, Edwards DR, Murphy G. Metalloproteinase inhibitors: biological actions and therapeutic opportunities. J Cell Sci 2002;115:3719-3727.

11. Kashiwagi M, Tortorella M, Nagase H, Brew K. TIMP-3 is a potent inhibitor of aggrecanase 1 (ADAM-TS4) and aggrecanase 2 (ADAM-TS5). J Biol Chem 2001;276:1250112504.

12. Brown PD. Ongoing trials with matrix metalloproteinase inhibitors. Expert Opin Investig Drugs 2000;9:2167-2177.

13. Bird J, Montana JG, Wills RE, Baxter AD, Owen DA. Selective matrix metalloproteinase (MMP) inhibitors having reduced side-effects. Chemical Abstracts 1999;129:225751.

14. Drummond AH, Beckett P, Brown PD, Bone EA, Davidson AH, Galloway WA, et al. Preclinical and clinical studies of MMP inhibitors in cancer. Ann N Y Acad Sci 1999;878: $228-235$.

15. Hutchinson JW, Tierney GM, Parsons SL, Davis TR. Dupuytren's disease and frozen shoulder induced by treatment with a matrix metalloproteinase inhibitor. J Bone Joint Surg 1998;80B:907-908.

16. Smith SP, Devaraj VS, Bunker TD. The association between frozen shoulder and Dupuytren's disease. J Shoulder Elbow Surg 2001;10:149-151.
17. Schaer H. Die atiologie der periarthritis humeroscapularis. Ergebn Chir Orthop 1936;29:11.

18. Ulrich D, Hrynyschyn K, Pallua N. Matrix metalloproteinases and tissue inhibitors of metalloproteinases in sera and tissue of patients with Dupuytren's disease. Plast Reconstr Surg 2003;112:1279-1286.

19. Qian A, Meals RA, Rajfer J, Gonzalez-Cadavid NF. Comparison of gene expression profiles between Peyronie's disease and Dupuytren's contracture. Urology 2004;64:399404.

20. Bunker TD, Reilly J, Baird KS, Hamblen DL. Expression of growth factors, cytokines and matrix metalloproteinases in frozen shoulder. J Bone Joint Surg 2000;82B:768-773.

21. Tarlton JF, Meagher P, Brown RA, McGrouther DA, Bailey AJ, Afoke A. Mechanical stress in vitro induces increased expression of MMPs 2 and 9 in excised Dupuytren's disease tissue. J Hand Surg 1998;23B:297-302.

22. Price JS, Waters JG, Darrah C, Pennington C, Edwards DR, Donell ST, Clark IM. The role of chondrocyte senescence in osteoarthritis. Aging Cell 2002;1:57-65.

23. Nuttall RK, Pennington CJ, Taplin J, Wheal A, Yong VW, Forsyth PA, Edwards DR. Elevated membrane-type matrix metalloproteinases in gliomas revealed by profiling proteases and inhibitors in human cancer cells. Mol Cancer Res 2003;1:333-345.

24. Porter S, Scott SD, Sassoon EM, Williams MR, Jones JL, Girling AC, et al. Dysregulated expression of adamalysinthrombospondin genes in human breast carcinoma. Clin Cancer Res 2004;10:2429-2440.

25. Clark IM, Parker AE. Metalloproteinases: their role in arthritis and potential as therapeutic targets. Expert Opin Ther Targets 2003;7:19-34.

26. Kevorkian L, Young DA, Darrah C, Donell ST, Shepstone L, Porter S, et al. Expression profiling of metalloproteinases and their inhibitors in cartilage. Arthritis Rheum 2004;50: 131-141.

27. Jones GC, Corps AN, Pennington CJ, Clark IM, Edwards DR, Bradley MM, et al. Expression profiling of metalloproteinases and tissue inhibitors of metalloproteinases in normal and degenerate human Achilles tendon. Arthritis Rheum 2006;54:832-842.

28. Jung SH, Bang H, Young S. Sample size calculation for multiple testing in microarray data analysis. Biostatistics 2005;6:157-169.

29. Bretz F, Landgrebe J, Brunner E. Multiplicity issues in microarray experiments. Methods Inf Med 2005;44:431-437.

30. Iredale JP. Cirrhosis: new research provides a basis for rational and targeted treatments. BMJ 2003;327:143-147.

31. Baragi VM, Fliszar CJ, Conroy MC, Ye QZ, Shipley JM, Welgus HG. Contribution of the C-terminal domain of metalloproteinases to binding by tissue inhibitor of metalloproteinases. C-terminal truncated stromelysin and matrilysin exhibit equally compromised binding affinities as compared to full-length stromelysin. J Biol Chem 1994;269:1269212697.

32. Bisson MA, Mudera V, McGrouther DA, Grobbelaar AO. The contractile properties and responses to tensional loading of Dupuytren's disease-derived fibroblasts are altered: a cause of the contracture? Plast Reconstr Surg 2004;113:611624.

33. Moyer KE, Banducci DR, Graham WP III, Ehrlich HP. 
Dupuytren's disease: physiologic changes in nodule and cord fibroblasts through aging in vitro. Plast Reconstr Surg 2002;110:187-196.

34. Tarpila E, Ghassemifar MR, Wingren S, Agren M, Franzen L. Contraction of collagen lattices by cells from Dupuytren's nodules. J Hand Surg 1996;21B:801-805.

35. Rayan GM, Tomasek JJ. Generation of contractile force by cultured Dupuytren's disease and normal palmar fibroblasts. Tissue Cell 1994;26:747-756.

36. Daniels JT, Cambrey AD, Occleston NL, Garrett Q, Tarnuzzer RW, Schultz GS, Khaw PT. Matrix metalloproteinase inhibition modulates fibroblast-mediated matrix contraction and collagen production in vitro. Invest Ophthalmol Vis Sci 2003;44:1104-1110.

37. Scott KA, Wood EJ, Karran EH. A matrix metalloproteinase inhibitor which prevents fibroblast-mediated collagen lattice contraction. FEBS Lett 1998;441:137-140.

38. Mirastschijski U, Haaksma CJ, Tomasek JJ, Agren MS. Matrix metalloproteinase inhibitor GM 6001 attenuates keratinocyte migration, contraction and myofibroblast formation in skin wounds. Exp Cell Res 2004;299:465475.
39. Unemori EN, Beck LS, Lee WP, Xu Y, Siegel M, Keller G, et al. Human relaxin decreases collagen accumulation in vivo in two rodent models of fibrosis. J Invest Dermatol 1993;101:280-285.

40. Unemori EN, Amento EP. Relaxin modulates synthesis and secretion of procollagenase and collagen by human dermal fibroblasts. J Biol Chem 1990;265:10681-10685.

41. Unemori EN, Pickford LB, Salles AL, Piercy CE, Grove $\mathrm{BH}$, Erikson ME, Amento EP. Relaxin induces an extracellular matrix-degrading phenotype in human lung fibroblasts in vitro and inhibits lung fibrosis in a murine model in vivo. J Clin Invest 1996;98:2739-2745.

42. Williams EJ, Benyon RC, Trim N, Hadwin R, Grove BH, Arthur MJ, et al. Relaxin inhibits effective collagen deposition by cultured hepatic stellate cells and decreases rat liver fibrosis in vivo. Gut 2001;49:577-583.

43. Le Goff C, Somerville RP, Kesteloot F, Powell K, Birk DE, Colige AC, Apte SS. Regulation of procollagen aminopropeptide processing during mouse embryogenesis by specialization of homologous ADAMTS proteases: insights on collagen biosynthesis and dermatosparaxis. Development 2006; 133:1587-1596. 